\title{
Há saída para a judicialização da assistência farmacêutica no Sistema Único de Saúde
}

There is a way out for the judicialization of pharmaceutical assistance in Brazilian Unified Health System

Hay salida para la judicialización de la asistencia farmacéutica en el Sistema Único de Salud de Brasil

\begin{abstract}
Resumo
Objetivo: evidenciar a necessidade da regulamentação de lacunas normativas pelo Ministério da Saúde de modo a concretizar o direito a medicamentos ausentes em relações e protocolos clínicos oficiais do Sistema Único de Saúde (SUS). Metodologia: foi utilizada a análise documental e legislativa. Resultados: atualmente as ações judiciais que visam ao fornecimento de medicamentos pelo SUS consomem sete bilhões de reais ao ano do orçamento público brasileiro, interferindo gravemente sobre as opções de investimento sanitário do gestor público. Evidenciam-se lacunas regulamentares em nível federal como potenciais causadoras do problema. Discussão: a eliminação de lacunas regulamentares pelo Ministério da Saúde se apresenta como medida capaz de reequilibrar a atuação dos Poderes em matéria de fornecimento de medicamentos pelo SUS. Conclusão: faz-se necessária a atuação do Ministério da Saúde, de forma a assegurar a permanente atualização do rol de medicamentos constantes nas relações e protocolos clínicos do SUS; a concessão excepcional de medicamentos não previstos para os casos cabíveis; e a seleção e remuneração adequada dos medicamentos oncológicos.
\end{abstract}

Palavras Chave: Sistema Único de Saúde. Gestão em saúde. Judicialização da saúde.

\begin{abstract}
Objective: to highlight the need for regulation of normative gaps by the Ministry of Health in order to realize the right to medicines absent in official Unified Health System lists and clinical protocols. Methodology: documentary analysis and legislative revision. Results: currently, legal actions aimed at supplying drugs by Unified Health System consume seven billion reais per year of the brazilian public budget, seriously interfering with public health investment options. Regulatory gaps at the federal level are evidenced as potential causes of the problem. Discussion: The elimination of regulatory gaps by the Ministry of Health presents itself as the option capable of rebalancing the performance of the Republic Powers regarding the supply of medicines by SUS. Conclusion: the Ministry of Health is required to ensure the permanent updating of the list of medicines contained in the Unified Health System 's clinical relations and protocols, the exceptional granting of medicines not provided for in appropriate cases, and adequate selection and remuneration of oncological drugs.
\end{abstract}

\footnotetext{
${ }^{1}$ Graduado em Ciências Jurídicas e Sociais pela PUCRS; pós-graduado em Interesses Difusos e Coletivos pela Escola Superior do Ministério Público do Estado do Rio Grande do Sul; analista do Ministério Público da União, Porto Alegre, Rio Grande do Sul, Brasil. E-mail: los2@outlook.com
} 
Keywords: Unified Health System. Health management. Judicialization of health.

\section{Resumen}

Objetivo: resaltar la necesidad de que el Ministerio de Salud regule las brechas regulatorias para hacer realidad el derecho a los medicamentos ausentes en protocolos clínicos oficiales y relaciones del Sistema Único de Salud (SUS). Metodología: se utilizó análisis documental y legislativa. Resultados: actualmente, las demandas dirigidas al suministro de medicamentos por el SUS consumen siete mil millones de reales por año del presupuesto público brasileño, lo que interfiere seriamente con las opciones de inversión en salud pública. Las brechas regulatorias a nivel federal se evidencian como causas potenciales del problema. Discusión: llenar los vacíos reglamentarios por parte del Ministerio de Salud se presenta como la opción capaz de reequilibrar el desempeño de los poderes de la República en relación con el suministro de medicamentos por parte del SUS. Conclusión: es necesario que el Ministerio de Salud actúe para garantizar la actualización permanente de la lista de medicamentos contenida en las relaciones y los protocolos clínicos del SUS, la concesión excepcional de medicamentos no provista para los casos apropiados y la selección y remuneración adecuada de los medicamentos contra el cáncer.

Palabras-llave: Sistema Único de Salud. Gestión de la salud. Judicialización de la salud.

\section{Introdução}

Alguns anos após a promulgação da Constituição Cidadã, em 1988 (1), os tribunais brasileiros, incentivados por nova jurisprudência do Supremo Tribunal Federal (STF), iniciaram uma honrosa jornada rumo ao reconhecimento da existência de uma ampla gama de direitos subjetivos a prestações sociais. No mesmo ritmo de crescimento em que esse movimento se verificou, observaram-se efeitos colaterais que passaram a impactar o orçamento e, de modo geral, os recursos à disposição da Administração Pública, tendo em vista os dispêndios envolvidos com a implementação dessa categoria de direitos.

Em matéria de saúde e, especialmente, de fornecimento de medicamentos pela rede pública de assistência, esses efeitos ganharam um volume que não se poderia mais ignorar nos últimos anos. Com o julgamento de um sempre crescente número de demandas individuais, o Poder Judiciário passou a reiterar, maciçamente, uma posição de ampla eficácia do direito fundamental à saúde, como decorrência direta do dever estatal previsto no art. 196 da Constituição: "a saúde é direito de todos e dever do Estado".

Em 2016, o então Ministro da Saúde, Ricardo Barros, já afirmava que o dispêndio dos governos brasileiros com a judicialização da saúde teria alcançado o patamar de sete bilhões anuais (2), informação que foi reiterada, em 2018, pelo Ministério da Saúde (3). A título 
comparativo, vale lembrar que o orçamento de 2019 de todo o Programa Mais Médicos foi da ordem de 3,6 bilhões de reais (4).

Segundo dados atualizados apresentados pela Advocacia-Geral da União, em maio de 2019, no julgamento do Recurso Extraordinário o 657.718 sobre o fornecimento de medicamentos sem registro na Anvisa pelo Sistema Único de Saúde (SUS), apenas os gastos da União com a judicialização da assistência farmacêutica estatal teriam crescido da ordem de $R \$ 200$ milhões no ano de 2011 para $R \$ 1,3$ bilhão em 2018 , sem contar os gastos relativos a depósitos judiciais (5). O cenário nos estados e municípios talvez seja tão ou mais grave. Apenas o estado de São Paulo, por exemplo, gasta mais de um bilhão ao ano para atender a ações judiciais em matéria de saúde, cuja maior parte diz respeito a medicamentos (6).

Todo esse montante de gastos, inevitavelmente, acaba por impactar a definição e a gestão das políticas públicas de saúde, de cunho universal e igualitário. Como arremata o Ministro Ricardo Barros: "o dinheiro da judicialização é deslocado de outras ações para atender à judicialização. Isso desestrutura o planejamento que foi feito para atender a população" (7).

Avizinhando-se a conclusão do julgamento do Recurso Extraordinário № 566.471 pela Suprema Corte - atinente ao fornecimento, pelo Poder Público, de medicamentos de alto custo não incorporados a relações e protocolos oficiais do SUS -, não se vislumbra perspectiva de mudança no cenário de profunda intervenção judicial sobre o orçamento estatal e, indiretamente, sobre a definição de políticas públicas. Tudo está a indicar a manutenção do entendimento - amplamente consolidado nas Cortes do país - de reconhecimento do apontado direito a medicamentos não previstos, desde que comprovado, na esfera do processo judicial, a efetiva necessidade da droga postulada, comparada às alternativas oficialmente previstas no sistema para o tratamento do requerente.

O presente artigo tem como objetivo evidenciar a necessidade da regulamentação de lacunas normativas pelo Ministério da Saúde, de modo a concretizar o direito a medicamentos ausentes em relações e protocolos clínicos oficiais do SUS, propiciando, ao Poder Judiciário, condições adequadas de análise de pretensas violações a esse direito.

A metodologia empregada ateve-se a pesquisas documental e bibliográfica, enfocadas notadamente em decisões de tribunais pátrios; documentos governamentais 
brasileiros; e publicações doutrinárias e pesquisas científicas igualmente nacionais. Foram analisados documentos e publicações variadas que abordassem direta ou indiretamente 0 fenômeno da judicialização da saúde, priorizando aqueles que apresentassem dados concernentes aos posicionamentos mais atuais dos Tribunais Superiores do país sobre a amplitude do direito ao fornecimento de medicamentos pelo SUS e a competência decisória sobre a seleção e atualização das relações de medicamentos fornecidas pelo sistema.

\section{O atual quadro de judicialização dos medicamentos fornecidos pelo SUS}

O fenômeno da judicialização da assistência farmacêutica prestada pelo SUS, que compõe predominantemente o quadro de demandas judiciais por prestações públicas de saúde, merece análise particularizada, pois está no centro do desequilíbrio de forças institucionais. Ações que versam sobre tratamentos médicos, consultas especializadas, internações ou cirurgias encontram uma natural e até mesmo profícua seara de ponderação em âmbito judicial, considerando-se, em especial, a clareza com que se descortina o conflito de interesses entre o autor e demais potenciais interessados: por um lado, fica manifesto ao juízo a necessidade de verificar se uma eventual sentença de procedência poderá resultar na preterição de interesse de igual ou maior relevância jurídica, titularizado por outras pessoas, notadamente pela burla de filas de espera. Por outro, os fundamentos da futura sentença podem ser razoavelmente construídos com base em informações prestadas pelas autoridades envolvidas, apresentação de documentos - como prontuários médicos - e provas periciais.

Quanto à demanda por medicamentos, em que não se patenteia uma concorrência clara de interessados, forma-se um falso cenário de inexistência de potenciais perdedores, ao prestigiar, na sentença, o direito à saúde, encartado no catálogo de direitos fundamentais da Constituição de 1988 (1). É claro que tal cenário não subsiste a um exame mais aprofundado, pois, sendo necessariamente finitos os recursos materiais à disposição da Administração Pública, fatalmente haverá interferência sobre as opções de custeio e investimento em prol de múltiplos interessados. Essa interferência se agrava no campo da saúde, cujo planejamento é realizado por diversos gestores de variadas instâncias governamentais e deve observar uma miríade de aspectos técnicos e políticos estabelecidas na complexa legislação do SUS. Não se trata, como bem pondera o Ministro Luís Roberto 
Barroso, de um mero conflito entre o direito à saúde e princípios de proteção orçamentária. Trata-se do conflito entre o direito à vida e à saúde de uns versus o direito à vida e à saúde de outros (8).

Após a análise de milhares de demandas por medicamentos, em anos de pronunciamentos, o Poder Judiciário brasileiro, por meio de seus Tribunais Superiores, vem sedimentando o entendimento de que o direito a medicamentos não incorporados ao SUS existe como decorrência da obrigação estatal constante do art. 196 da Constituição Federal, desde que comprovada a efetiva necessidade do remédio postulado, consideradas as alternativas já previstas - rectius, incorporadas - em relações e protocolos oficiais do sistema para o tratamento do paciente.

Em 2018, o Superior Tribunal de Justiça (STJ) julgou o Recurso Especial RE no 1.657.156 em regime de recurso repetitivo (art. 1.036 do CPC) (9), confirmando de modo geral essa orientação e estabelecendo a seguinte tese, que deve ser observada pelas Cortes inferiores:

\begin{abstract}
Constitui obrigação do Poder Público o fornecimento de medicamentos não incorporados em atos normativos do SUS, desde que presentes, cumulativamente, os requisitos fixados neste julgado, a saber:

I - Comprovação, por meio de laudo médico fundamentado e circunstanciado expedido por médico que assiste o paciente, da imprescindibilidade ou necessidade do medicamento, assim como da ineficácia, para o tratamento da moléstia, dos fármacos fornecidos pelo SUS;

II - Incapacidade financeira de arcar com o custo do medicamento prescrito; e

III - Existência de registro na ANVISA do medicamento (10, grifo do autor).
\end{abstract}

O órgão pleno do STF, por sua vez, segue esse mesmo caminho no julgamento do Recurso Extraordinário no 566.471 , no qual já foram proferidos os votos dos Ministros Marco Aurélio, relator; Edson Fachin; e Luís Roberto Barroso, todos alinhados com o posicionamento sufragado no STJ. O Ministro relator, na última assentada, em aditamento a seu voto após a apresentação do voto-vista do ministro Barroso, apresentou a seguinte tese para fins de repercussão geral:

O reconhecimento do direito individual ao fornecimento, pelo Estado, de medicamento de alto custo, não incluído em política nacional de medicamentos ou em programa de medicamentos de dispensação em caráter excepcional, constante de rol dos aprovados, depende da demonstração da imprescindibilidade - adequação e necessidade -, da impossibilidade de 
substituição, da incapacidade financeira do enfermo e da falta de espontaneidade dos membros da família solidária em custeá-lo, respeitadas as disposições sobre alimentos dos artigos 1.649 a 1.710 do Código Civil e assegurado o direito de regresso (11, grifo do autor).

O Ministro Luís Roberto Barroso, a propósito, fez proposta parecida em seu voto-vista, mas adicionando um requisito negativo relevante para um eventual juízo de procedência em âmbito judicial individual: "inexistência de uma decisão expressa da Conitec ${ }^{2}$ desfavorável à incorporação pelo SUS" (12).

Cabe uma crítica, de qualquer modo: a competência para decidir sobre o fornecimento de medicamentos no SUS é, de modo geral, do Ministério da Saúde ${ }^{3}$, a quem cabe levar em conta aspectos orçamentários e sociais não abarcados na recomendação da Comissão. O Ministério, afinal, também profere decisões de não incorporação, competindo à pasta determinar o que o sistema deve fornecer aos usuários, em nível cautelar ou definitivo. Esse, no nosso entendimento, deveria ser o ponto de ponderação buscado pelo ministro: inexistência de decisão, cautelar ou definitiva, do Ministério da Saúde, no sentido de o SUS não incorporar ou não fornecer o medicamento.

Como se percebe, na trilha aberta pelo STJ, a mais alta Corte do país tenciona esposar, em definitivo, a posição segundo a qual o usuário do SUS tem direito a medicamentos inicialmente não previstos pelo sistema para o tratamento de sua moléstia, ainda que sujeito a determinadas condições, fundamentalmente a prova concreta de sua necessidade. Esse entendimento, que faz coro com a jurisprudência dos tribunais inferiores, abre uma incontestável exceção ao disposto nos arts. 19-M a 19-Q da Lei no 8.080/90, a denominada Lei Orgânica do SUS, ou seja, flexibiliza a previsão de que os medicamentos alcançados pelo sistema aos seus usuários devem ser aqueles previstos em protocolos e relações oficiais, formalmente incorporados por decisão do Ministério da Saúde com base em processo administrativo de rito específico, instruído na Conitec, no qual se deve perquirir não somente sobre a sua eficácia, acurácia, efetividade e segurança, mas em que também

\footnotetext{
${ }^{2}$ A Comissão Nacional de Incorporação de Tecnologias (Conitec) é órgão de assessoramento do Ministro da Saúde que realiza a análise técnica de novas tecnologias conforme processo legalmente estabelecido, recomendando-lhe ou não a incorporação ao SUS, dentre outras atribuições.

3 É verdade que estados e municípios podem complementar as relações federais de medicamentos, mas, como explicitado na Lei 8.080/90 e pela Lei 12.401/11, sempre de forma suplementar ao quanto já definido em nível federal; segundo decidido, aliás, pela Comissão Intergestores Tripartite no âmbito da assistência farmacêutica, apenas quando o perfil epidemiológico da localidade e questões de saúde pública assim justificarem (arts. 9o e 10 da Resolução CIT 25/17).
} 
se deve realizar uma "avaliação econômica comparativa dos benefícios e dos custos em relação às tecnologias já incorporadas" (art. 19-Q) (13).

O posicionamento judicial dominante, acima apresentado, aparentemente contém burla ao processo administrativo de incorporação de tecnologias, no qual, por força de lei, não se deve investigar apenas o benefício clínico do medicamento cuja incorporação é analisada, mas o custo de seu fornecimento universalizado em perspectiva com o que mais poderia ser feito em termos de investimento em saúde no âmbito do SUS. É o que a lei denomina de exame do custo-efetividade da tecnologia (art. 19-O, parágrafo único) (13). Tal estudo pode demorar bem mais que 180 dias para ser concluído e a um custo considerável. Um exemplo é o chamamento público lançado, em 2018, pelo Hospital Alemão Oswaldo Cruz, em conjunto com o Departamento de Ciência e Tecnologia da Secretaria de Ciência, Tecnologia e Insumos Estratégicos do Ministério da Saúde. O respectivo edital, que tinha por escopo a seleção de projetos de avaliação de custo-efetividade de várias tecnologias na perspectiva do SUS, previa prazo de 240 dias para entrega do trabalho de pesquisa e financiamento previsto de 90 mil reais (14).

A confecção de um estudo econômico no campo da análise de tecnologias em saúde, nessa perspectiva, dificilmente poderia ser levada a efeito em juízo, considerando que os autores de ações de fornecimento de medicamentos pelo SUS habitualmente litigam sob o pálio da gratuidade de justiça (15). Estudos elaborados na perspectiva de sistemas de saúde estrangeiros também encontram importantes obstáculos para serem utilizados, de modo originário em processos judiciais nacionais, uma vez que, de modo geral, não realizam análise comparativa do medicamento almejado com as alternativas fornecidas pelo SUS, considerando seus efeitos sobre a população brasileira especificamente, que possui diversas peculiaridades, inclusive regionais.

Além disso, a via de exceção perfilhada pelos tribunais brasileiros aparentemente também vai de encontro à autonomia dos demais poderes na definição das políticas públicas. Como determinar, em nível judicial, se o recurso que será contingenciado para a aquisição do medicamento postulado não deveria ser aproveitado em ações outras, como de saneamento básico ou de atendimento materno-infantil? Vale lembrar que essas iniciativas, citadas como exemplos, são específica e constitucionalmente protegidas (CF/88, arts. 23, inciso IX; 198, II; 200, IV; 227, § 1) (1). Não são questões meramente técnicas, mas também 
políticas, não há dúvida.

Porém, mesmo não observando o cenário mais amplo da assistência farmacêutica no SUS, não se vislumbra equívoco na decisão das Cortes Superiores. O direito fundamental à saúde, cujo dever de implementação é do Estado, possui alta densidade normativa na ordem constitucional brasileira, exigindo-lhe fazer o máximo que estiver ao seu alcance para concretizá-lo em plenitude, no resguardo da vida e da saúde da população. O Supremo Tribunal Federal, em julgamento de relatoria do ministro Celso de Mello, já teve oportunidade de afirmar:

O sentido de fundamentalidade do direito à saúde - que representa, no contexto da evolução histórica dos direitos básicos da pessoa humana, uma das expressões mais relevantes das liberdades reais ou concretas - impõe ao Poder Público um dever de prestação positiva que somente se terá por cumprido, pelas instâncias governamentais, quando estas adotarem providências destinadas a promover, em plenitude, a satisfação efetiva da determinação ordenada pelo texto constitucional (16, grifo do autor).

O disposto no art. $2^{\circ}$ da Lei $n^{\circ}$ 8.080/90 reflete e concretiza esse mandado constitucional (13). Ainda que o processo de incorporação de novos medicamentos ao SUS (arts. 19-Q e 19-R) esteja sujeito a fatores muitas vezes imponderáveis - ou mesmo ponderáveis, mas de consequências inevitáveis, como a necessidade de razoável tempo para que se promova uma análise que possibilite uma decisão de fundo e definitiva -, o mandamento de plenificação não poderia ser adequadamente cumprido pelo Poder Público, se não fosse ofertado a possibilidade, observados parâmetros mínimos previamente estabelecidos, de excepcionar a regra aos usuários, de modo a autorizar o fornecimento urgente de medicamento ainda não formalmente incorporado ao SUS.

Por mais que o Ministério da Saúde e seu órgão de assessoria, a Conitec, se tornem diligentes em matéria de incorporações, ao procurar manter o catálogo de medicamentos ofertados pelo SUS fielmente atualizado, haverá casos em que o mandado constitucional de proteção à vida e à saúde da pessoa fatalmente demandará a abertura de uma exceção. Afinal, a vida, nem a saúde do indivíduo, podem ficar sujeitas a um processo burocrático em certos casos. Às vezes, o instrumento deve ceder à substância; o Estado não existe como um fim em si mesmo. Múltiplos fatores econômicos, sociais, jurídicos, uns previsíveis, outros não, podem causar demora deletéria aos usuários do SUS no exame de incorporação de medicamentos, justificando-se a existência do canal de exceção referendado pelo STJ e, em 
vias de endosso, pelo STF.

Porém, por absoluta falta de dados fundamentais - relativos a todos os aspectos econômicos e sociais inerentes a uma tomada de decisão sobre o fornecimento estatal de certo medicamento -, o Poder Judiciário quase sempre acaba por proferir sentenças, na maioria das vezes de procedência, com frágil fundamentação, por mais que se desdobre na procura da solução, que deve ser legitimamente extraída do ordenamento jurídico. Há de se reconhecer que lhe é completamente inviável concluir, originariamente, sobre a juridicidade da negativa administrativa de fornecimento, quando baseada exclusivamente na ausência de previsão em lista ou protocolo do SUS. O problema, felizmente, pode ser remediado, principalmente por meio de uma análise prévia e de fundo do pleito excepcional pela própria Administração Pública, mas que, atualmente, depende de regulamentação.

\section{Primazia da decisão sobre o fornecimento de medicamentos ausentes em relações e protocolos do SUS}

A discussão acerca da pertinência clínica dos medicamentos judicialmente postulados não deve causar maior embaraço à instrução processual, sendo esse um dado equacionável dentro do processo, seja por meio de perícias e análise de documentação médica, seja por intermédio de consultas em bancos de pareceres técnicos ou a núcleos técnicos de apoio, dentre outras medidas passíveis de adoção.

O problema reside na dificuldade em se identificar, em âmbito processual, a existência ou não de uma omissão ilícita do Poder Público na decisão administrativa que nega o medicamento almejado, prescrito, aliás, por médico do próprio sistema. Essa é uma questão essencial que facilmente se pode passar ao largo em razão da falta de elementos adequados de ponderação, invocando-se a fundamentalidade do direito à saúde, de ordinário, como tábua de salvação. Seria meramente a negativa administrativa, conjugada à comprovação da superior eficácia do medicamento postulado para o tratamento do autor, suficiente para atestar a ilicitude do posicionamento do ente público? Teria o direito fundamental à saúde caráter absoluto, de modo a sempre obrigar o Estado à prestação em saúde que se comprove a mais eficaz? É evidente que não (17); a integralidade da assistência estatal diz respeito, como regra, aos produtos e serviços incorporados a relações e protocolos do SUS, na forma da lei (Lei o 8.080/90, art. 19-M) (13), o que está de acordo com o disposto na 
Constituição Federal, já que a obrigação estatal com a saúde se concretiza seletivamente (art. 194, inciso III) e "mediante políticas sociais e econômicas" (art. 196), escolhidas pelas vias democráticas, segundo critérios de justiça social (art. 193) (1).

Vale lembrar que a jurisdição contenciosa exige a existência de um litígio, que se instala a partir da imputação de um ato ou fato àquele que é demandado em juízo, subjacente à relação jurídica que se quer ver declarada ou protegida. Além disso, esse ato ou fato deve ser antijurídico, considerando que a Lei Orgânica do SUS prevê quais medicamentos serão providos pelo sistema público de saúde - aqueles constantes de relações e protocolos oficiais - e como esses instrumentos serão atualizados - mediante submissão de pedido de incorporação ou desincorporação à Conitec -, por intermédio de um processo administrativo em que os princípios constitucionais da igualdade, seletividade, eficiência e fonte de custeio devem ser observados.

A concessão judicial de um medicamento não previsto deveria, portanto, basear-se sobretudo em uma falha imputável ao Poder Público nesse processo; não seja isso, então na constatação de que a própria Administração Pública deveria, quando provocada, ter aberto uma exceção na via administrativa para atender ao caso concreto. De todo modo, a falha estatal deverá se descortinar, neste último caso considerando ser o Poder Público detentor das condições técnicas e especialmente políticas para avaliar e decidir originariamente sobre a existência de um dever de excepcionar a regra.

Para além da eficácia clínica do medicamento postulado para o tratamento do autor, comparada às alternativas já formalmente previstas pelo SUS, seria fundamental perquirir: (a) se a hipótese trazida a juízo antes aportou como pedido de incorporação à Comissão Nacional de Incorporação de Tecnologias e qual o resultado, em caso afirmativo; (b) não tendo aportado, se existiu algum obstáculo imputável à própria Administração Pública que possa fundamentar, ainda que parcialmente, um dever de excepcionar a regra da prévia incorporação ao SUS; (c) se a Administração Pública debruçou-se sobre o requerimento administrativo do autor e efetivamente avaliou, segundo critérios abstrata e previamente definidos, a possibilidade de ressalvar essa regra (excepcionalidade juridicamente reconhecida pelas Cortes do país) em face de razões que justifiquem essa grave decisão excepcional. Aqui, vale ressaltar que o tema já havia sido abordado pelo Ministro Gilmar Mendes, quando do julgamento da Suspensão de Tutela Antecipada no 175, em 2010: 
Quanto aos novos tratamentos (ainda não incorporados pelo SUS), é preciso que se tenha cuidado redobrado na apreciação da matéria. Como frisado pelos especialistas ouvidos na Audiência Pública, o conhecimento médico não é estanque, sua evolução é muito rápida e dificilmente suscetível de acompanhamento pela burocracia administrativa.

Se, por um lado, a elaboração dos Protocolos Clínicos e das Diretrizes Terapêuticas privilegia a melhor distribuição de recursos públicos e a segurança dos pacientes, por outro a aprovação de novas indicações terapêuticas pode ser muito lenta e, assim, acabar por excluir o acesso de pacientes do SUS a tratamento há muito prestado pela iniciativa privada.

Parece certo que a inexistência de Protocolo Clínico no SUS não pode significar violação ao princípio da integralidade do sistema, nem justificar a diferença entre as opções acessíveis aos usuários da rede pública e as disponíveis aos usuários da rede privada. Nesses casos, a omissão administrativa no tratamento de determinada patologia poderá ser objeto de impugnação judicial, tanto por ações individuais como coletivas.

[...]

Ademais, não se pode esquecer de que a gestão do Sistema Único de Saúde, obrigado a observar o princípio constitucional do acesso universal e igualitário às ações e prestações de saúde, só torna-se viável mediante a elaboração de políticas públicas que repartam os recursos (naturalmente escassos) da forma mais eficiente possível. Obrigar a rede pública a financiar toda e qualquer ação e prestação de saúde existente geraria grave lesão à ordem administrativa e levaria ao comprometimento do SUS, de modo a prejudicar ainda mais o atendimento médico da parcela da população mais necessitada. Dessa forma, podemos concluir que, em geral, deverá ser privilegiado o tratamento fornecido pelo SUS em detrimento de opção diversa escolhida pelo paciente, sempre que não for comprovada a ineficácia ou a impropriedade da política de saúde existente.

Essa conclusão não afasta, contudo, a possibilidade de o Poder Judiciário, ou de a própria Administração, decidir que medida diferente da custeada pelo SUS deve ser fornecida a determinada pessoa que, por razões específicas do seu organismo, comprove que o tratamento fornecido não é eficaz no seu caso. Inclusive, como ressaltado pelo próprio Ministro da Saúde na Audiência Pública, há necessidade de revisão periódica dos protocolos existentes e de elaboração de novos protocolos (18, grifo do autor).

Compete à própria Administração Pública avaliar administrativamente e com primazia se não é o caso de excepcionar a regra e fornecer o medicamento ao paciente, ainda que não previsto em relação ou protocolo oficial do SUS, seja por identificar falha no processo de incorporação de novas tecnologias que assim - e em algum nível - o justifique, seja por entender, de forma ampla, tratar-se da solução que se impõe ao caso concreto a fim de que se observe, em plenitude, o direito fundamental à saúde. As razões para a adoção da medida excepcional pela administração podem, conjugadas ou não, ser múltiplas: desde a identificação de uma desatualização crônica da política pública vigente - quer dizer, da 
relação oficial de medicamentos ou do protocolo clínico aplicável -, até a percepção de que o benefício gerado ao paciente entelado - um recém-nascido em risco de vida, por exemplo - justifica juridicamente esse fornecimento. Para essa decisão, a ser tomada em nível municipal, estadual ou federal, conforme regulamento, a Administração poderá lançar mão de critérios consagrados pelo Poder Judiciário, como laudo expedido por médico do SUS que ateste a superior eficácia do medicamento postulado perante as tecnologias já ofertadas pelo sistema e a hipossuficiência econômica do interessado, dentre outros que reputar adequados. Entretanto, Ihe caberá verificar a pertinência econômica e social do fornecimento excepcional - sendo esses os dados cruciais que não se consegue alcançar originariamente no processo judicial, mas que o ordenamento protege e deixa a cargo do administrador público analisar -, ainda que em análise não exauriente e sob o prisma da eventual universalização dessa decisão, por imperativo do princípio da igualdade $(\mathrm{CF} / 88$, art. 5ํㅡ, caput; art. 196) (1).

Será sobre essa decisão que o Poder Judiciário terá condições adequadas de se debruçar, avaliando todos os aspectos para decidir sobre a sua juridicidade. Conclui, com perspicácia, Tais Dórea de Carvalho Santos:

Bastava, porém, um mínimo de bom senso para se verificar que a escassez de recursos é uma realidade, que se agrava num país de extrema desigualdade e dimensões continentais. Não existem recursos disponíveis para a investidura em todos os pontos possíveis a se trabalhar, nem ao menos aos mais relevantes, sendo a escassez a regra e não a exceção.

Assim, em sua função de gestor, o Estado tem uma quantidade ilimitada de obrigações (incluindo nessas os direitos fundamentais) e orçamento limitado. Quais direitos serão priorizados é uma tarefa que cabe ao Estado (legislativo/executivo), baseada nas necessidades mais urgentes da população. A certeza dos direitos constitucionais, trazidos de maneira expressa e inquestionável, não reverbera em recursos, infelizmente.

Havendo desmandos e desvios, o judiciário deve ser convocado para delimitar os limites legais dessa atuação. Mas não se pode deixar de compreender que a própria Administração Pública deverá ser o "primeiro juiz", ou seja, ela tem que verificar se está fazendo o certo, o ideal (19). (grifo do autor).

É verdade que a Administração Pública não terá condições de providenciar prontamente um estudo de custo-efetividade para embasar sua decisão, mas contará com dados e condições técnicas bem mais factíveis para verificar se não é o caso e também se Ihe é financeiramente possível fornecer o medicamento pleiteado, fazendo-o de modo 
cautelar. É preciso lembrar que a incorporação de medicamentos ao SUS deve ser realizada por meio de um processo administrativo, contando o administrador com prerrogativa legal similar ao juízo, consistente em expedir atos cautelares, prévios ou incidentais ao processo, a fim salvaguardar o bem jurídico protegido de um eventual perecimento, conforme previsto no art. 45 da Lei no 9.784/99 (20), que se aplica ao processo de incorporação na forma do art. 19-R, § 1ำ, da Lei no 8.080/90 (13) e dos arts. 28, 29 e 33 do dos arts. 28, 29 e 33 do Decreto no 7.646/11 (21).

Também é verdade que as secretarias de saúde, que recebem os requerimentos, dependem da regulamentação desse dever-poder estatal cautelar pelo Ministério da Saúde para definir responsabilidades, operacionais e financeiras, e estabelecer quais critérios, de modo universal e igualitário, serão aplicados na análise excepcional de requerimentos de medicamentos não previstos pelo SUS. O dever de regulamentação se extrai principalmente da obrigação federal de promover a descentralização das ações e serviços de saúde às secretarias estaduais e municipais, prevista no art. 16, inciso XV, da Lei oㅗ 8.080/90, onde deverão ser localmente executados e prestados à população (13); se colhe também da cláusula de financiamento tripartite do SUS, constitucionalmente prevista (CF/88, art. 198, § $\left.1^{\circ}\right)$ (1). Para realizar essa descentralização, o Ministério da Saúde se serve de um poder regulamentar implícito, normatizando e coordenando o SUS em suas mais diversas ações e serviços. Sem essa diretriz, as secretarias de saúde de estados e municípios se veem, efetivamente, impossibilitadas de analisar as demandas excepcionais ou dar encaminhamento ao gestor responsável - conforme definido no regulamento -, pela falta de pactuação quanto aos encargos financeiros e administrativos entres as três instâncias federativas, que, de regra, não podem ser suportados isoladamente pelas secretarias demandadas sem prejuízo do equilíbrio federativo, especialmente no que toca à medicação de alto custo ainda não incorporada pelo SUS.

Ao regulamentar a Lei Orgânica do SUS no campo do fornecimento de medicamentos pelo sistema, o art. 28 do Decreto № 7.508/11 concretiza autorização ao Poder Público para realizar a dispensação excepcional em questão, nos seguintes termos:

Art. 28. O acesso universal e igualitário à assistência farmacêutica pressupõe, cumulativamente:

I - estar o usuário assistido por ações e serviços de saúde do SUS; 
II - ter o medicamento sido prescrito por profissional de saúde, no exercício regular de suas funções no SUS;

III - estar a prescrição em conformidade com a RENAME e os Protocolos Clínicos e Diretrizes Terapêuticas ou com a relação específica complementar estadual, distrital ou municipal de medicamentos; e

IV - ter a dispensação ocorrido em unidades indicadas pela direção do SUS. $\S 1 \%$. Os entes federativos poderão ampliar o acesso do usuário à assistência farmacêutica, desde que questões de saúde pública o justifiquem.

$\S 2^{\circ}$. O Ministério da Saúde poderá estabelecer regras diferenciadas de acesso a medicamentos de caráter especializado. (22, grifos do autor).

Na falta dessa solução, o Poder Judiciário permanecerá fatalmente sem condições de realizar uma análise adequada de muitas demandas judiciais por medicamentos, já que em cerca de $80 \%$ delas se buscam medicamentos fora da lista do SUS, segundo pesquisas enfocadas no Rio de Janeiro e em Brasília (23 e 24).

O processo de incorporação jamais será tão ótimo que exclua qualquer necessidade de tutelar excepcionalmente o caso concreto em nome da vida e da saúde, valores constitucionais essenciais. Por mais sedutora que a ideia se apresente, não é adequado o Judiciário exercer essa função originariamente, sob pena de incontornável ofensa à separação de poderes, que se traduz na completa falta de legitimidade do órgão judicante para decidir, primariamente e sem elementos, sobre a pertinência econômica e social da dispensação pretendida. Concretamente, o fará tateando no escuro como atualmente ocorre, ou, então, como se advoga neste artigo, debruçando-se sobre dados palpáveis de um exame já realizado pelo agente público competente, segundo regras definidas em regulamento. Esse ato normativo também estará sujeito a escrutínio pelo Ministério Público e de outros órgãos legitimados a essa fiscalização.

Alguns estados já vêm realizando ações no sentido de analisar administrativamente requerimentos de medicamentos ausentes em protocolos e relações oficiais do SUS, de modo a reduzir a judicialização e a fomentar a eficiência do gasto público. É o caso de São Paulo, por meio do programa Acessa SUS, encabeçado pela Defensoria Pública do Estado e que teria reduzido o número de ajuizamentos pelo órgão em cerca de 70\%, em 2017 (6). Outro exemplo recente é o Estado do Rio Grande do Sul, em que se verificou redução expressiva no número de demandas individuais ajuizadas a partir de iniciativa similar (25).

Fundamental, nesse cenário, que tais decisões cautelares sejam proferidas prévia ou incidentalmente ao processo formal de incorporação, o único habilitado a estabelecer em 
definitivo se as listagens do SUS devem ou não ser efetivamente modificadas. Daí se concluir que o entelado procedimento de concessão excepcional de medicamentos deve ser monitorado a fim de que resulte, nos casos que não se resolvam de outra forma, em uma análise definitiva no órgão federal competente (Conitec/MS), de modo a atingirem-se os ideais de igualdade, de promoção de justiça social e de máxima eficácia do direito fundamental à saúde, princípios reitores do sistema.

\section{O papel subsidiário do Ministério da Saúde como garantia da atualização permanente das relações e protocolos do SUS}

Não são poucos os obstáculos a enfrentar para que se instale um razoável processo de atualização do rol de medicamentos previstos no SUS. Entretanto, mesmo que esses entraves fossem superados, nada nem ninguém poderia garantir que outros, imprevisíveis, viessem a surgir. Isso, por si só, justifica a existência de um canal permanente para a análise de casos especiais que possam exigir uma tutela administrativa cautelar específica, sendo uma decorrência do comando constitucional de máxima proteção da vida e da saúde da pessoa, como acima defendido.

Porém, não se pode inverter a lógica do sistema, de modo que a atualização constante das incorporações deverá ser sempre prioritária e desejável frente às vias excepcionais. Será exatamente nas eventuais lacunas que a administração poderá atuar cautelarmente perante o caso concreto. Esse é o modo instituído pelo legislador para que o SUS preste um serviço igualitário para toda a população usuária: na forma do caput do art. 19-Q da Lei 8.080/90 (13), compete ao Ministro da Saúde - assessorado pela Conitec - decidir, em definitivo, quais prestações serão ofertadas universalmente, em nível nacional.

O obstáculo mais evidente e sanável, por ser de natureza eminentemente jurídica, diz respeito ao franqueamento do acesso à Conitec e à deflagração do processo de novas incorporações, que é demasiadamente restrito por conta de omissão ilícita do Ministério da Saúde. Atualmente, a Comissão exige, dos eventuais interessados em submeter um novo pedido de incorporação, a apresentação de "estudo de avaliação econômica comparando a tecnologia pautada com as tecnologias em saúde disponibilizadas no SUS", previsto no Decreto no 7.646/11 (21). É possível que muitas entidades interessadas na incorporação de tecnologias ao SUS, como associações de pacientes, no entanto, não tenham condições 
econômicas de providenciar ditos estudos.

A Lei no 8.080/90, regulamentada pelo citado decreto, não faz tal exigência com a amplitude prevista no regulamento (13). O art. 19-R, § 1丷, inciso I, da Lei Orgânica do SUS demanda do interessado que instrua seu pedido com a apresentação de documentos contendo as informações necessárias à elaboração do relatório que a Conitec deverá submeter ao Ministério da Saúde, acompanhado de um parecer (rectius: recomendação), dando margem a questionamentos sobre a extensão da obrigação a que está sujeito o proponente da incorporação.

O ordenamento, como se sabe, deve ser interpretado sistematicamente, a partir do texto constitucional sobretudo. Saúde é dever do Estado (CF/88, art. 196), que deve ser exercido de modo a propiciar acesso universal e igualitário à população (art. 196) e a promover justiça social (art. 193), esta é a realidade do dever estatal (1). Se o referido proponente não possui condições econômicas de apresentar tal estudo - e documento não é o mesmo que estudo-, mas apenas documentos que permitam a um terceiro confeccionálos, não se pode afastar a obrigação estatal de preencher essa lacuna, se for necessário, na falta de outra forma instituída pelo legislador.

O próprio Ministério da Saúde é proponente habitual de novas incorporações à Conitec (26) e serve-se de uma rede de instituições de saúde para confeccionar o estudo entelado, para as quais realiza chamamentos públicos (27). Assim, a pasta possui reais condições de avaliar se deve confeccionar o estudo de custo-efetividade na perspectiva do SUS caso o proponente não tenha condições de fazê-lo, sem prejuízo de realizar uma avaliação prévia em que se constate que o pedido deva ser preliminarmente negado por motivo outro. Outra opção é a encampação do pedido pelo Ministério da Saúde, já que o art. 15 do Decreto ํㅜ 7.646/11 lhe autoriza fazer a proposição, mesmo sem a apresentação de um específico estudo de custo-efetividade (21). A imposição da obrigação de entrega de tal trabalho científico de forma generalizada, como se vê, impõe ônus demasiado à camada hipossuficiente da sociedade, que deve ser assistida pelo próprio Estado como decorrência do seu dever constitucional, em especial porque a lei não prevê que o pedido de incorporação seja instruído com o referido estudo.

Os obstáculos não se resumem a essa dificuldade atinente à deflagração do processo de avaliação junto à Conitec, alcançando motivos de ordem econômica e social, muitas 
vezes insondáveis, que impedem que a proposta de incorporação seja efetivamente submetida. Um caso frequente é a falta de interesse da indústria farmacêutica em formalizála. O setor farmacêutico dificilmente deixará de ponderar, de um lado, com a incerteza do acolhimento do pedido na Comissão - até porque o Brasil não possui limiares de custoefetividade oficialmente fixados, diminuindo a previsibilidade sobre o quanto será decidido e, de outro, com o atual sucesso obtido em demandas judiciais individuais (28).

Tais circunstâncias são comuns no caso de medicamentos para doenças raras - cuja exigência de registro foi indevidamente relativizada no julgamento do Recurso Extraordinário no 657.718, potencializando o fenômeno da judicialização sem necessidade -, já que muitos possuem baixíssimo custo-efetividade, ou seja, são muito dispendiosos, gerando baixa produção relativa de retorno em benefício sanitário (29). É bom que se lembre que as demandas individuais por medicamentos órfãos (para doenças raras) representam, grosso modo, cerca de $70 \%$ do gasto federal com judicialização, conforme estudo da Interfarma, de 2018 (30). Outras vezes poderá haver simples desinteresse econômico na proposição, dentre outros fatores imprevisíveis.

Todo este cenário de incertezas exige do Poder Público uma observação vigilante sobre as demandas individuais por medicamentos pelo SUS, anguladas administrativa ou judicialmente. Não há outra forma de assegurar a permanente atualização dos protocolos e relações oficiais do sistema frente aos anseios que se consubstanciam nesses requerimentos, porque não se pode garantir que os atores sociais legitimados, que atuam quase sempre em nome de interesses próprios, farão a provocação necessária, em tempo oportuno e obedecendo a toda formalidade exigida, do órgão federal de avaliação. Muitos são os interesses que não encontrarão representação perante a Conitec.

Mais do que isso, essa observação permanente deve resultar em uma decisão administrativa, cautelar ou definitiva (neste caso, uma vez concluído o processo formal de incorporação na Conitec), a ser proferida pelo Ministério da Saúde, que assegure a igualdade no sistema em nível nacional e mantenha o Poder Público como o primeiro juiz a se posicionar. É válido mencionar que a Comissão de Incorporação de Tecnologias já vem proferindo decisões preliminares de forma a recomendar ou não ao Ministério da Saúde, em análise não exauriente e sujeita a retificação, a incorporação do medicamento ao SUS, o que é indício de que o gestor federal realmente possui meios de adiantar-se frente a algumas 
demandas. Foi o caso da abiraterona para o tratamento de câncer de próstata ${ }^{4}{ }^{5}$.

\section{O caso especial dos medicamentos oncológicos}

O modelo de seleção e financiamento dos medicamentos oncológicos fornecidos pelo SUS, como se sabe, não segue a regra geral aplicável à assistência farmacêutica prestada aos seus usuários, conforme regulamentação vigente em nível nacional. Desde que inaugurado o modelo de remuneração individualizada dos serviços de alta complexidade prestados pelo SUS, em 1996 (Portaria MS no 2.043/96), o Ministério da Saúde incluiu nessa formatação - as chamadas autorizações de procedimentos ambulatoriais de alta complexidade/custo (Apac) - todo o serviço de assistência oncológica do SUS, inclusive o fornecimento de medicamentos oncológicos (31).

Nesse método, os hospitais e centros de saúde credenciados possuem autonomia para definir seus próprios elencos de medicamentos e são remunerados segundo a tabela de procedimentos do SUS pelo serviço globalmente prestado - v.g., tratamento quimioterápico para câncer de pulmão metastático -, um preço fixo que independe do esquema de drogas efetivamente utilizado. Dentro desse valor, o hospital operaria com certa margem de escolha, o que é habitualmente ressaltado pelo Ministério da Saúde, mas é falacioso, como se verá.

Preliminarmente, é importante ressaltar que cabe ao Ministério da Saúde decidir como será feito o fornecimento excepcional de medicamentos quimioterápicos no contexto do procedimento cautelar cuja adoção é advogada nesse artigo. $O$ fato é que a assistência farmacêutica oncológica do SUS, por estar inserida na sistemática de prestação de serviços, tem dois graves entraves, mas que felizmente também são passíveis de correção, conforme passamos a expor.

O primeiro deles diz respeito à seleção dos quimioterápicos que serão fornecidos pelo sistema. Desde a edição da Lei no 12.401/11 (32), que alterou substancialmente a Lei

\footnotetext{
${ }^{4}$ Decisão disponível em: http://conitec.gov.br/images/Consultas/Relatorios/2019/Relatorio_Abiraterona_Adenocarcinomade-prostata-resistente-a-castrao-em-pacientes-com-uso-prvio-de-quimioterapia_CP_26_2019.pdf

${ }^{5}$ Cabe anotar que tramita, na Justiça Federal do Rio Grande do Sul, ação civil pública proposta pelo Ministério Público Federal que tem por objetivo final "a operacionalização de um ciclo resolutivo que permita o pleno exercício do direito fundamental social à saúde, no que toca à assistência farmacêutica e de produtos para a saúde, pela população usuária do SUS, balizado por um permanente e efetivo processo de avaliação, escolha e atualização a ser realizado pelas instâncias legislativas e administrativas competentes" e que, em boa medida, abarca o exercício do dever-poder regulamentar tratado neste artigo (processo 5035904-91.2017.4.04.7100).
} 
Orgânica do SUS, a decisão sobre a incorporação de novos medicamentos - sejam eles para o tratamento de que doenças forem - passou a obedecer um roteiro estrito de atos, a iniciar pela submissão de pedido formal à Conitec, seguida de uma análise criteriosa, culminando em uma decisão final do Ministério da Saúde (Lei o 8.080/90, arts. 19-Q e 19R) (13). Esse procedimento complexo tem por objetivo garantir uma decisão o mais justa possível no cenário de perene escassez de recursos e que atenda à população usuária do SUS de forma universal, igualitária, integral e eficiente, que são seus pilares fundamentais. No entanto, sem observar a alteração legislativa, o Ministério da Saúde não passou a observar o novo regramento no campo da assistência farmacêutica oncológica, escorandose no argumento de que as incorporações, nesse caso, são de procedimentos, mantendo a pretensa liberdade dos hospitais para escolherem seu arsenal de drogas.

A lei, todavia, é clara em determinar que toda incorporação de novos medicamentos - quaisquer medicamentos - deve ser submetida ao roteiro acima explicitado, no que acertou o legislador, já que cada droga possui custo e eficácia muito diversos. Contraditoriamente, o próprio Ministério da Saúde passou a realizar algumas incorporações de medicamentos oncológicos, notadamente para realizar a aquisição centralizada de alguns deles ${ }^{6}$, mas manteve, paralelamente e como sistema principal, a seleção fragmentária realizada pelos hospitais habilitados pelo SUS (Portaria MS № 140/14, art. 13, inciso VI) (33), resultando em um sistema misto não albergado em lei.

Primeiramente, se nota haver uma indevida delegação de responsabilidade aos hospitais (Cacon e Unacon). A responsabilidade financeira pelo custeio da quimioterapia no SUS é da União, por integrar o serviço de alta complexidade, na forma da Norma Operacional de Assistência à Saúde de 2002. No entanto, como é fixado um teto de repasse pelo Ministério da Saúde - teto da média e alta complexidade -, é o próprio Ministério quem cegamente baliza, pelo teto repassado, as opções dos hospitais. Assim, não há a propalada ampla liberdade de hospitais e centros de saúde em suas escolhas. Mesmo que houvesse ampliação do referido teto, considerando que não existe nem poderia existir um controle sobre o orçamento de cada hospital, ainda assim cada um deles faz as escolhas que julgar mais adequadas à sua realidade financeira, resultando na completa desigualdade na

\footnotetext{
${ }^{6}$ Mesilato de imatinibe, trastuzumabe, I-asparaginase, talidomida, rituximabe, dasatinibe, dactinomicina e nilotinibe, cada uma para o tratamento de um tipo específico de neoplasia. Vide http://www.saude.gov.br/noticias/817-assuntos/atencaoespecializada-e-hospitalar/40675-tratamento-e-reabilitacao.
} 
prestação do serviço pelo país afora. Vale citar o estudo Diferenças no tratamento sistêmico do câncer no Brasil: meu SUS é diferente do teu SUS, encartado na revista Brazilian Journal of Oncology, de 2017, que aponta a gravidade da disparidade da quimioterapia fornecida nos diversos hospitais habilitados (34). Fere-se, assim, o pilar central do sistema, que é a igualdade de acesso às suas prestações. Há também o agravante de jamais se saber até onde vai a obrigação do SUS - qual o meu direito como usuário? -, já que cada hospital tem capacidade financeira distinta e opera suas escolhas com base em sua realidade única.

O Ministério da Saúde, nas poucas incorporações de medicamentos que realiza como, por exemplo, dos medicamentos erlotinibe e gefitinibe, para câncer de pulmão -, formaliza sua decisão assentando unilateralmente que não fará alterações no valor de ressarcimento via APAC, sob a justificativa de que o valor pago pelo procedimento previsto na tabela do SUS se opera em regime de compensação com outros medicamentos oncológicos menos custosos. Não há como verificar a veracidade do argumento. $O$ fato incontestável é que toda incorporação de nova tecnologia deveria passar pelo crivo da Comissão Intergestores Tripartite (CIT), colegiado de representantes da União, Estados e Municípios que tem por competência decidir sobre o financiamento das novas incorporações, como determina o art. 19-U da Lei Orgânica do SUS (13). Nela, são ouvidos todos os interessados no tema; caberia, sem dúvida, colher o parecer dos estabelecimentos de saúde habilitados em oncologia, uma vez que são, atualmente, os responsáveis por indevidamente selecionar $\mathrm{e}$ - adquirir os medicamentos incorporados.

Para garantir a igualdade de tratamento a todos e a eficiência do sistema, a seleção dos medicamentos oncológicos a serem fornecidos pelo SUS deveria ser realizada pelo Ministério da Saúde, que também é o responsável direto pelo seu financiamento. As incorporações formais desses medicamentos, ainda, deveriam ser submetidas à CIT, órgão verdadeiramente responsável por determinar se o valor de ressarcimento das APACs deve ou não ser revisto.

\section{Considerações finais}

De modo geral, é forçoso reconhecer que o Sistema Único de Saúde não conta com mecanismos regulamentares eficientes de atualização do rol de medicamentos constantes de seus protocolos clínicos e relações oficiais. Em grande parte, essa lacuna se evidencia 
pela omissão ilícita do órgão coordenador do sistema em nível federal, ou seja, do Ministério da Saúde, que: (a) não regulamentou o processo de dispensação excepcional de medicamentos ausentes nos referidos instrumentos para casos que esta medida cautelarmente se justifique, com repartição de responsabilidades pactuadas previamente entre os três níveis federativos; (b) não propicia condições para que entidades economicamente hipossuficientes possam submeter pedidos de incorporação à Comissão Nacional de Incorporação de Tecnologias no SUS; (c) não monitora as demandas individuais, administrativas e judiciais, proferindo, quando reputado oportuno, uma decisão cautelar ou definitiva de incorporação que oriente todos os atores envolvidos, de modo a dar tratamento igualitário às hipóteses em nível nacional.

Passados 30 anos de vigência da Constituição Cidadã, que fixou o direito fundamental à saúde como um dever estatal de alta densidade normativa, os tribunais pátrios reafirmam diariamente e de forma pacífica a existência de um direito subjetivo a medicamentos ausentes em relações oficiais e protocolos clínicos do SUS, preenchidos alguns requisitos. Em 2019, o Supremo Tribunal Federal deverá coroar esse entendimento ao concluir o julgamento do Recurso Extraordinário № 566.471, que já tem três votos favoráveis em plenário.

$\mathrm{Na}$ falta do exercício do dever-poder regulamentar pelo Ministério da Saúde, acima enquadrado, apenas ter-se-á a consolidação do grave quadro de intervenção judicial no orçamento público, que atualmente atinge a cifra de 7 bilhões anuais, com a substituição danosa do gestor público pelo juiz.

O fornecimento de medicamentos oncológicos pelo SUS tem suas próprias dificuldades, uma vez que a seleção do elenco de opções não vem sendo definido - de forma igualitária e universal - pelo Ministério da Saúde como determina a lei, mas fragmentariamente pelos hospitais habilitados à prestação do serviço, segundo a realidade financeira de cada um. Uma vez realizada a incorporação formal, competiria à Comissão Intergestores Tripartite analisar a suficiência do repasse financeiro federal para o seu financiamento, uma vez que a União é o ente responsável pelo custeio da atenção oncológica, o que não vem sendo observado pelo Ministério da Saúde. 


\section{Referências}

1. Brasil. Constituição da República Federativa do Brasil, 8 de outubro de 1988. Disponível em: http://www.planalto.gov.br/ccivil_03/Constituicao/Constituicao.htm [Acesso em 8.out.2019].

2. Laboissière P. Judicialização da saúde desestrutura planejamento do governo, diz ministro. EBC. 28 set. 2016. Disponível em: http://agenciabrasil.ebc.com.br/geral/noticia/ 2016-09/judicializacao-da-saude-desestrutura-planejamento-do-governo-diz-ministro [Acesso em 26.jun.2019].

3. Gebran Neto JP. Direito à saúde: eficiência do sistema de saúde pública. VI Fórum Jurídico de Lisboa: reforma do Estado Social no contexto da globalização. 3 abr 2018. Disponível em: http://forumjuridicodelisboa.com/2018/wp-content/uploads/2018/04/JoãoPedro-Gebran-Neto.pdf [Acesso em 26.jun.2019].

4. Brasil. Lei no 13.808 , de 15 de janeiro de 2019. Estima a receita e fixa a despesa da União para o exercício financeiro de 2019. Brasília, 15 jan 2019. Disponível em: http://www.planalto.gov.br/ccivil_03/_ato2019-2022/2019/Lei/L13808.htm [Acesso em 5.jul.2019].

5. Advocacia-Geral da União. AGU alerta para riscos de obrigar SUS a fornecer remédio sem eficácia comprovada. AGU. 22 mai 2019. Disponível em: https://www.agu.gov.br/page/ content/detail/id_conteudo/756819 [Acesso em 26.jun.2019].

6. Crepaldi T, Moraes C. Com judicialização da saúde, juízes passam a ditar políticas públicas do setor. ConJur. 15 ago 2018. Disponível em: https://www.conjur.com.br/2018-ago15/judicializacao-saude-juizes-passam-ditar-politicas-publicas-setor [Acesso em 26.jun.2019].

7. Oliveira N. País busca soluções para aumento de judicialização na saúde. Senado Notícias. 15 mai 2018. Disponível em: https:/www12.senado.leg.br/noticias/especiais/ especial-cidadania/pais-busca-solucoes-para-aumento-de-judicializacao-na-saude [Acesso em 26.jun.2019].

8. Barroso LR. Da falta de efetividade à judicialização excessiva: direito à saúde, fornecimento gratuito de medicamentos e parâmetros para a atuação judicial. Juris Plenum: Direito Administrativo, 2014, 1(1): 25-50.

9. Brasil. Lei no 13.105, de 16 de março de 2015. Código de Processo Civil. Disponível em: http://www.planalto.gov.br/ccivil_03/_ato2015-2018/2015/lei/13105.htm [Acesso em 8.out.2019].

10. Brasil. Superior Tribunal de Justiça. Recurso Especial 1.657.156. Recorrente: Estado do Rio de Janeiro. Recorrida: Fatima Theresa Esteves do Santos de Oliveira. Relator: Ministro Benedito Gonçalves. Brasília, 25 abr 2018. Diário de Justiça Eletrônico. Disponível em: https://ww2.stj.jus.br/processo/dj [Acesso em 27.jun.2019]. 
11. Brasil. Supremo Tribunal Federal. Brasil. Aditamento ao voto do relator no Recurso Extraordinário 566.471. Recorrente: Estado do Rio Grande do Norte. Recorrido: Carmelita Anunciada de Souza. Relator: Ministro Marco Aurélio. Brasília, 28 set. 2016. Disponível em: http://www.stf.jus.br/arquivo/cms/noticiaNoticiaStf/anexo/RE566471aditamento.pdf [Acesso em 27.jun.2019].

12. Brasil. Supremo Tribunal Federal. Brasil. Voto-vista no Recurso Extraordinário 566.471. Recorrente: Estado do Rio Grande do Norte. Recorrido: Carmelita Anunciada de Souza. Relator: Ministro Marco Aurélio. Brasília, 28 set. 2016. Disponível em: http://www.luisrobertobarroso.com.br/wp-content/uploads/2016/10/RE-566471-Medicamentos -de-alto-custo-versão-final.pdf [Acesso em 27.jun.2019].

13. Brasil. Lei no 8.080, de 19 de setembro de 1990. Dispõe sobre as condições para a promoção, proteção e recuperação da saúde, a organização e o funcionamento dos serviços correspondentes e dá outras providências. Disponível em: http://www.planalto.gov.br/ ccivil_03/leis//8080.htm Acesso em: [Acesso em 8.out.2019].

14. Hospital Alemão Oswaldo Cruz. Chamada de apoio financeiro a estudos de avaliação de tecnologias em saúde. 28 set. 2018. Disponível em: https://hospitaloswaldocruz.org.br/wpcontent/uploads/2018/10/edital_2018_28set_.pdf [Acesso em 8.out.2019].

15. Carvalho VA. A judicialização da saúde sob o olhar da Análise Econômica do Direito: um exame dos incentivos ao ajuizamento e à solução extrajudicial de conflitos. Revista brasileira de políticas públicas. Dez 2018. Disponível em: https://www.publicacoesacademicas.uniceub.br/ RBPP/article/view/5676/pdf [Acesso em 8.out.2019].

16. Brasil. Supremo Tribunal Federal. Recurso Extraordinário 271.286. Recorrente: Município de Porto Alegre. Recorrido: Estado do Rio Grande do Sul. Relator: Ministro Celso de Mello. Brasília, 12 set. 2000. Diário de Justiça de 24 nov. 2000.

17. Machado DG. Judicialização Excessiva x Ausência de Políticas Públicas: Ponderação nas Decisões Judiciais, Separação dos Poderes e o Direito à Saúde. Artigo científico apresentado à Escola de Magistratura do Estado do Rio de Janeiro, como exigência para obtenção do título de Pós-graduação. Jan. 2010. Disponível em: http://www.emerj.tjrj.jus.br/paginas/trabalhos_conclusao/2semestre2010/trabalhos_22010/d aniellemachado.pdf [Acesso em 8.out.2019].

18. Brasil. Supremo Tribunal Federal. Agravo Regimental na Suspensão de Tutela Antecipada 175. Requerente: União. Requerido: Tribunal Regional Federal da $5^{\underline{a}}$ Região. Relator: Ministro Gilmar Mendes. Brasília, 17 mar. 2010. Diário de Justiça Eletrônico 76, de 29 abr. 2010.

19. Santos TDC. Estudo das escolhas trágicas à luz do princípio da eficiência e os precedentes judiciais. Repositório Institucional da Universidade Federal da Bahia. 28 mai. 2015. Disponível em: https://repositorio.ufba.br/ri/handle/ri/17781 [Acesso em 2.jul.2019]. 
20. Brasil. Lei no 9.784/93, de 29 de janeiro de 1999. Regula o processo administrativo no âmbito da Administração Pública Federal. Disponível em: http://www.planalto.gov.br/ccivil_03/ leis/19784.htm [Acesso em 8.out.2019].

21. Brasil. Decreto oㅜ 7.646, de 21 de dezembro de 2011. Dispõe sobre a Comissão Nacional de Incorporação de Tecnologias no Sistema Único de Saúde e sobre o processo administrativo para incorporação, exclusão e alteração de tecnologias em saúde pelo Sistema Único de Saúde - SUS, e dá outras providências. Disponível em: http://www.planalto.gov.br/ccivil_03/_Ato2011-2014/2011/Decreto/D7646.htm [Acesso em 8.out.2019].

22. Brasil. Decreto o 7.508, de 28 de junho de 2011. Regulamenta a Lei no 8.080, de 19 de setembro de 1990, para dispor sobre a organização do Sistema Único de Saúde - SUS, o planejamento da saúde, a assistência à saúde e a articulação interfederativa, e dá outras providências. Disponível em: http://www.planalto.gov.br/ccivil_03/_Ato2011-2014/2011/ Decreto/D7508.htm [Acesso em 8.out.2019].

23. Pepe VLE et al. Caracterização de demandas judiciais de fornecimento de medicamentos "essenciais" no Estado do Rio de Janeiro, Brasil. Cad. Saúde Pública. Rio de Janeiro, v. 26, n. 3, p. 461-471, $2010 \mathrm{~b}$.

24. Sant'Ana RNA. Saúde aos cuidados do judiciário: a judicialização das políticas públicas de assistência farmacêutica no Distrito Federal a partir da jurisprudência do TJDFT. 2009. 159 p. Dissertação (Mestrado em Direito) - Faculdade de Direito, Universidade de Brasília, Brasília.

25. Schulze M. A Desjudicialização da Saúde no Rio Grande do Sul: Cabal Redução do Número das Ações Ativas e Estratégia de Interiorização. Coletânea direito à Saúde: Boas Práticas e Diálogos Institucionais. Brasília. CONASS; 2018. p. 196-208.

26. Brasil. Comissão Nacional de Incorporação de Tecnologias no SUS. Tecnologias demandadas. Disponível em: http://conitec.gov.br/tecnologias-em-avaliacao [Acesso em 4.jul.2019].

27. Brasil. Ministério da Saúde. Ministério da Saúde e OPAS financiarão sete estudos sobre resistência aos antimicrobianos. Notícias SCTIE. 14 mar. 2018. Disponível em: http://www.saude.gov.br/noticias/sctie/42824-ministerio-da-saude-e-opas-financiarao-seteestudos-sobre-resistencia-aos-antimicrobianos [Acesso em 4.jul.2019].

28. Chieffi AL, Barata RCB. Ações judiciais: estratégia da indústria farmacêutica para introdução de novos medicamentos. Revista de Saúde Pública. 2010 jun: 44 no. 3.

29. Silva EN, Souza, TRV. Avaliação econômica no âmbito das doenças raras: isto é possível?, Brasil. Cad. Saúde Pública. Rio de Janeiro, v. 31, n. 3, p. 496-506, 2015. 
30. Interfarma. Doenças Raras: A urgência do acesso à saúde. Fev 2018. Disponível em: https://www.interfarma.org.br/public/files/biblioteca/doencas-raras--a-urgencia-do-acesso-asaude-interfarma.pdf [Acesso em 4.jul.2019].

31. Brasil. Portaria MS no 2.043, de 11 de outubro de 1996. Determina a implantação da autorização de procedimentos ambulatoriais de alta complexidade/custo - apac, instrumento específico para autorização, cobrança e informações gerenciais dos procedimentos de alta complexidade/custo e do fornecimento de medicamentos excepcionais, realizados pelas unidades prestadoras de serviços, cadastradas no sistema de informações ambulatoriais do sistema unico de saude - sia/sus. Diário Oficial da União [da] República Federativa do Brasil. (14 dez. 1996); Seção1, 20798.

32. Brasil. Lei 12.401, de 28 de abril de 2011. Altera a Lei no 8.080, de 19 de setembro de 1990, para dispor sobre a assistência terapêutica e a incorporação de tecnologia em saúde no âmbito do Sistema Único de Saúde - SUS. Disponível em: http://www.planalto.gov.br/ ccivil_03/_ato2011-2014/2011/lei//12401.htm [Acesso em 8.out.2019].

33. Brasil. Portaria MS 140, de 27 de fevereiro de 2014. Redefine os critérios e parâmetros para organização, planejamento, monitoramento, controle e avaliação dos estabelecimentos de saúde habilitados na atenção especializada em oncologia e define as condições estruturais, de funcionamento e de recursos humanos para a habilitação destes estabelecimentos no âmbito do Sistema Único de Saúde (SUS). Disponível em: http://bvsms.saude.gov.br/bvs/saudelegis/sas/2014/prt0140_27_02_2014.html [Acesso em 8.out.2019].

34. Kaliks RA, Matos TF, Silva VA, Barros LHC. Diferenças no tratamento sistêmico do câncer no Brasil: meu SUS é diferente do teu SUS. Braz J Oncol. 2017; 13(44):1-12.

Stédile LO. Há saída para a judicialização da assistência farmacêutica no Sistema Único de Saúde. Cadernos IberoAmericanos de Direito Sanitário. 2019 out./dez.; 8(4): 78-102.

http://dx.doi.org/10.17566/ciads.v8i4.533 